\title{
Pharmacological Properties of Avicennia marina (Forssk) Vierh
}

\author{
P. Arockia Mary Fernandez, D. Vasumathi, S. Lingathurai* and S. \\ Lokkirubhar \\ Department of Zoology and Research Centre, Aditanar College of Arts and Science, \\ Tiruchendur - 628 216, Tamil Nadu, India.
}

Received: 16 Oct 2020 / Accepted: 14 Nov 2020/ Published online: 01 Jan 2021 *Corresponding Author Email: lings02@gmail.com

\begin{abstract}
Avicennia marina is the marine mangrove found abundantly along the coastal regions of Thoothukudi District. It is enriched with numerous bioactive compounds having wide range of medicinal properties. In this study, A.marina was extracted with five different solvents viz. hexane, water, isopropanol, acetone and methanol. Different solvent extracts of $A$. marina was subjected to biochemical assays viz. Total antioxidant activity, Protein denaturation inhibition activity, Nitric oxide scavenging activity and Metal chelating ability. Methanolic extract of A.marina shown highest activity in all the biochemical assays. Hence, the methanolic extract can be used a source of drug for various diseases.
\end{abstract}

Keywords

Avicennia marina, Antioxidant, Nitric oxide scavenging and Metal chelating study.

\section{INTRODUCTION:}

Plants are the very important chemical factories of nature. Plants produce a diverse range of bioactive molecules, making them rich sources of different types of medicine. Today most of the drugs are obtained from natural sources or semi synthetic derivatives of natural products and used in the traditional systems of medicine. Thus it is a logical approach in drug discovery to screen traditional natural products. Approximately $20 \%$ of the plants found in the world have been submitted to pharmaceutical or biological test and a sustainable number of new antibiotics introduced on the market are obtained from natural or semi synthetic resources (Panda, 2000).

Phytochemicals are the natural bioactive compounds found in plants. They are divided into two groups which are primary metabolites and secondary metabolites according to their functions in plant metabolism. Primary metabolites comprise common sugars, amino acids, proteins and chlorophyll while secondary metabolites consist of alkaloids, flavonoids, tannins, saponins, terpenoids and phenolic compounds (Edeoga et al., 2005; Prasad et al., 2012). Most of the novel bioactive principles of plants constituted by secondary metabolites like alkaloids, terpenoids, flavonoids, phenolic compounds, organic acids and lipids (Harborne,1998).

The present study aimed to utilize the mangrove plant which is one of the important sources of mangrove. They are widespread in tropical and subtropical regions, growing in the saline intertidal zones of sheltered coast lines (Chelliah, 2001; Marium Tariq et al., 2007). Mangrove species are woody, seed bearing and highly specialized plants (Duke et al., 1998) found coast lines of estuaries and lagoons (Kamaruzzaman, 2011). Because of their unique adaptations mangroves thrive well in the environment where other plants cannot grow (Shanmugapriya et al., 2012). Mangroves are salt tolerant plants. The specific regions where plants 
occur are termed as mangrove ecosystem (Kathiresan et al., 2001; Chelliah, 2001). There are seven species of true mangroves have been identified are also recorded. Mangrove plants also have been also used as traditional medicine in India (Dhayanithi et al., 2012; Bharathi et al., 2011).

However during the last decade screening of mangroves for bioactive compounds (Kokpal et al., 1990), has received high interest as a potential bioresource for novel bioproduct leads (Ishibasi et al., 1993; Miki et al., 1994). Among all the true mangroves of the world Avicennia marina (Forsk.) Vierh is a valuable mangrove because of its medicinal values and abundant distribution.

A. marina is commonly called white mangrove belongs to the family Avicenniaceae. It is a small medium sized tree (3-11 meter) with many branches. Extensive underground root system with Pencil root (Pneumatophores or breaking roots) up to $90 \mathrm{~mm}$ long. The plant has received some attention in determining its important chemical constituents. Phenolic compounds are secondary plant metabolites and are involved in a wide range of specialized physiological function (Bharathi et al., 2011; Dhayanithi et al., 2012; Borojeni et al., 2013). Previous reports suggest that this species was useful in stabilizing banks of estuaries in salty water and that it has tannin rich bark (Bandaranayake, 2002). In this study pharmaceutical properties of Avicennia marina was evaluated using certain in vitro assays viz. Total antioxidant activity, nitric oxide scavenging activity, protein denaturation inhibition activity and chelating ability of metal ions.

\section{MATERIALS AND METHODS: \\ Collection and Identification of plant Avicennia marina}

The fresh leaf of mangrove plant, Avicennia marina was collected from the estuarine region of Roche Park of Thoothukudi district, South East Coast of Tamil Nadu, India by hand picking method. The leaves were washed thoroughly thrice with tap water and once with sterile distilled water to remove salt and sand. Then they were shade dried for two weeks and were partially powdered using domestic blender and stored in air tight container for further use.

\section{Extraction}

Extraction was carried out by using cold percoalation method. An amount (100 gm) of partially crushed and powdered leaves was taken separately into 1000 $\mathrm{ml}$ of conical flask with acetone, hexane, methanol, isopropanol and sterilized water individually. This set up was kept on a rotary shaker at $120 \mathrm{rpm}$ for $24 \mathrm{hrs}$. After shaking, it was filtered through eight layers of muslin cloth, $100 \mathrm{ml}$ of extract was centrifuged at
$5000 \times \mathrm{g}$ for $15 \mathrm{~min}$. Extraction of solvent was evaporated and dried over Sodium Sulphate in desiccator under vacuum.

Total antioxidant activity of $A$. marina by Phosphomolybdenum assay

Total antioxidant activity was estimated by phosphomolybdenum assay (Prieto et al, 1999). A. marina extracts of different concentration ranging from $200 \mu \mathrm{g} / \mathrm{ml}$ to $1000 \mu \mathrm{g} / \mathrm{ml}$ were taken in individual test tubes and made up to $1 \mathrm{ml}$ using distilled water and $2 \mathrm{ml}$ of Molybdate reagent solution (0.6 M sulfuric acid, $28 \mathrm{mM}$ sodium phosphate and $4 \mathrm{mM}$ ammonium molybdate) was added. The tubes were incubated at $95^{\circ} \mathrm{C}$ for 90 minutes. After incubation, the tubes were cooled to room temperature for 20-30 min and the absorbance of the reaction mixture was measured at $695 \mathrm{~nm}$. Experiments were done in triplicates. Ascorbic acid was used as the positive reference standard.

Protein denaturation inhibition activity of $A$. marina extract

The reaction mixture $(0.5 \mathrm{ml})$ consisted of $0.45 \mathrm{ml}$ bovine serum albumin ( $5 \%$ aqueous solution) and 0.1 $\mathrm{ml}$ of A.marina extract at different concentration (200-1000 $\mathrm{\mu g} / \mathrm{ml})$ was taken in test tubes and incubated at $37^{\circ} \mathrm{C}$ for $30 \mathrm{~min}$ (Tanford, 1968). After cooling the samples, $2.5 \mathrm{ml}$ phosphate buffer saline $(\mathrm{pH}$ 6.3) was added to each tube. Turbidity was measured spectrophotometrically at $660 \mathrm{~nm} .0 .5 \mathrm{ml}$ distilled water was used as blank. The percentage inhibition of protein denaturation was calculated by the following formula,

Percent protein denaturation inhibition $=$ Abs control Abs sample / Abs control X 100

Nitric oxide scavenging activity of $\boldsymbol{A}$. marina

Nitric oxide scavenging activity can be estimated by the use of Griess reaction (Garrat, 1964). The compound sodium nitroprusside decomposes in aqueous solution at physiological $\mathrm{pH}$ (7.2) producing nitric oxide. Under aerobic conditions, nitric oxide reacts with oxygen to produce stable products (nitrate and nitrite). The quantities of nitrate and nitrite can be determined using Griess reagent (1\% sulfanilamide, $2 \% \mathrm{H}_{3} \mathrm{PO}_{4}$ and $0.1 \% \mathrm{~N}$-(1-naphthyl) ethylenediamine dihydrochloride). Scavengers of nitric oxide compete with oxygen leading to reduced production of nitrite ions. For the experiment, sodium nitroprusside $(10 \mathrm{mM})$ in phosphate buffered saline was mixed with different concentrations (200$1000 \mu \mathrm{g} / \mathrm{ml}$ ) of A.marina extract and incubated at 30 ㄷ for 2 hours. After the incubation period, $0.5 \mathrm{ml}$ of Griess reagent was added. The absorbance of the chromophore that formed during diazotization of the nitrite with sulfanilamide and subsequent coupling with Naphthyl ethylenediamine dihydrochloride was 
immediately read at $540 \mathrm{~nm}$. Inhibition of nitrite formation by the crude extracts and the standard antioxidant ascorbic acid were calculated relative to the control. All experiments were performed in triplicates and the results were expressed as mean \pm standard deviation.

Chelating ability of $\boldsymbol{A}$. marina extract on ferrous ions The ferrous ion chelating potential of the extracts was evaluated by Dinis et al. method. The reaction mixture contained $1.0 \mathrm{ml}$ of various concentrations of the extracts $(2-10 \mathrm{mg} / \mathrm{ml})$ and $0.05 \mathrm{ml}$ of $2 \mathrm{mM}$ $\mathrm{FeCl}_{3}$. The reaction was initiated by the addition of $0.2 \mathrm{ml}$ of $5 \mathrm{mM}$ ferrozine. The reaction mixture was shaken vigorously and left standing at room temperature for $10 \mathrm{~min}$ and the absorbance of the reaction mixture was measured at $562 \mathrm{~nm}$ against a reagent blank. A lower absorbance of the reaction mixture indicated a higher ferrous ion chelating ability. The control contained all the reagents except sample. Gallic acid and ascorbic acid was used as standard for comparison. The following formula was used to calculate percent inhibition.

Percent Inhibition $=[($ Control- Test $) /$ control $] \times 100$

\section{RESULTS AND DISCUSSION:}

The total antioxidant activity of $\boldsymbol{A}$. marina extract The total antioxidant activity is the representation of the compounds ability to neutralize or scavenge free electrons in biological system. Activity of different extracts of A.marina was shown in Figure 1 . Methanolic extract of $A$. marina shown highest activity followed by acetone, isopropanol, aqueous and hexane. Ascorbic acid was used as control. The results indicated that methanolic extract of A.marina has contained highest concentration of bioactive compounds with anticancer activity. Sharma S and and Vig AP, (2013) studied in vitro antioxidant properties using methanol and aqueous extracts of Parkinsonia aculeata and found that different phytochemicals, present in the leaves, are responsible for the high antioxidant potential. Samydurai et al., 2012 also observed hydroxyl group of the phenolic group donate to superoxide scavenging activity by their electron donor. Kumaran and Karunakaran, 2006 investigated that the antioxidant properties of methanol extract of Cardiospermum halicacabum engaging b-carotenelinoleate model system, 1,1-diphenyl-2picrylhydrazyl (DPPH) superoxide nitric oxide radical scavenging, reducing power, and iron ion chelating activity
Nitric oxide is the important free radical cause severe damage to DNA and proteins. The drug molecules of nitric oxide scavenging potential with less side effects will be the better drug than chemically derived counterparts. The nitric oxide scavenging activity of different extracts of A.marina was shown in Figure 2. Methanolic extract of $A$. marina shown highest activity followed by acetone, isopropanol, aqueous and hexane. Ascorbic acid was used as control. Awah and Verla, 2010 studied that Ocimum gratissimum leaf extract possesses high antioxidant and nitric oxide scavenging activity. Pacher et al., 2007 and Sreejayan \& Rao, 1997 revealed that toxicity of nitric oxide increases their superoxide to combine oxidant contribute $\mathrm{OH}$ group and nitric oxide.

Proteins are the essential biomolecules in human body. The destruction of proteins results in progression of diseases such as alzheimers and Parkinson. The drugs having protein denaturation inhibition activity be used as drugs for protein related diseases (Williams et al., 2008). Many literatures revealed that plant extracts possess protein denaturation (Mitul and Handral, 2013, Mohan et al., 2013, Madduluri et al., 2014, Sarkar, 2015). Protein denaturation inhibition activity of different extracts of $A$. marina was shown in Figure 3. Methanolic extract of $A$. marina shown highest activity followed by acetone, isopropanol, aqueous and hexane.

Metal chelating property is a sign of antioxidant activity; it reduces the concentration of the catalyzing transition (Duh et al., 1999). Fe (III) reduction is often used as an indicator of electron donating activity, which is an important mechanism of phenolic antioxidant action. The reducing ability of a compound generally depends on the presence of reductones (antioxidants), which exert the antioxidant activity by breaking the free radical chain by donating a hydrogen atom. Metal chelating activity of different extracts of $A$. marina was shown in Figure 4. Methanolic extract of A.marina shown highest activity followed by acetone, isopropanol, aqueous and hexane. This hypothesis is also confirmed by numerous reports in the literature showing that cytotoxic herbal extracts and isolated phytochemicals frequently also reveal antioxidant activity (Adam et al., 2018, Duh et al., 1999). Ascorbic acid was used as control. 
Figure1. Total Antioxidant activity of $\boldsymbol{A}$. marina extract

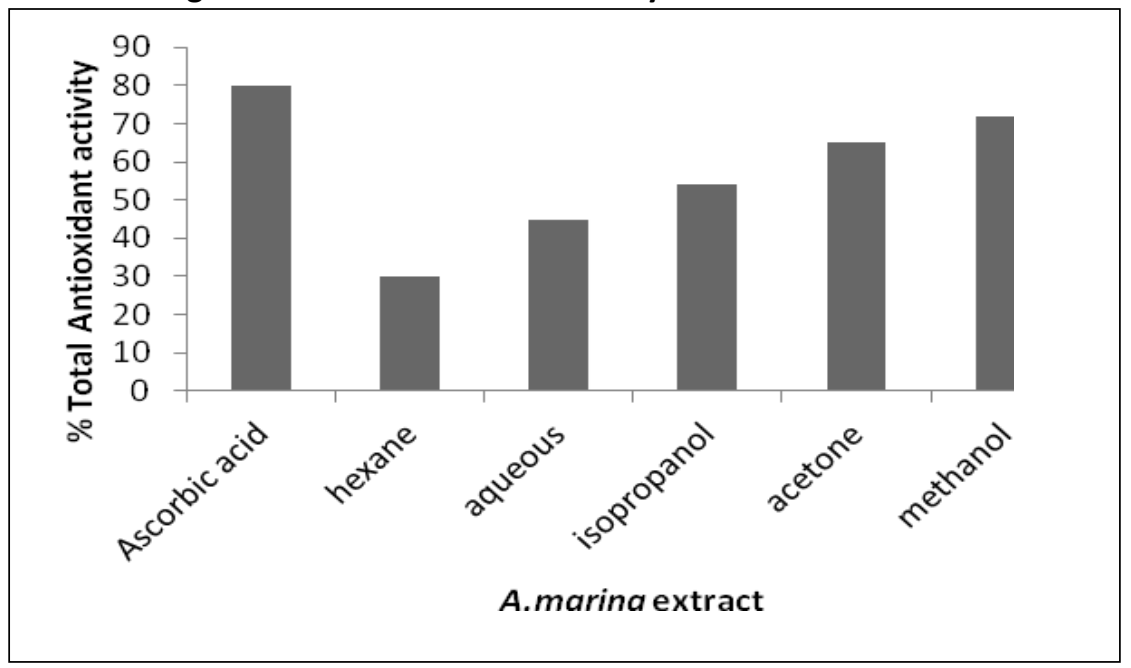

Figure 2. Nitric oxide scavenging activity of A.marina

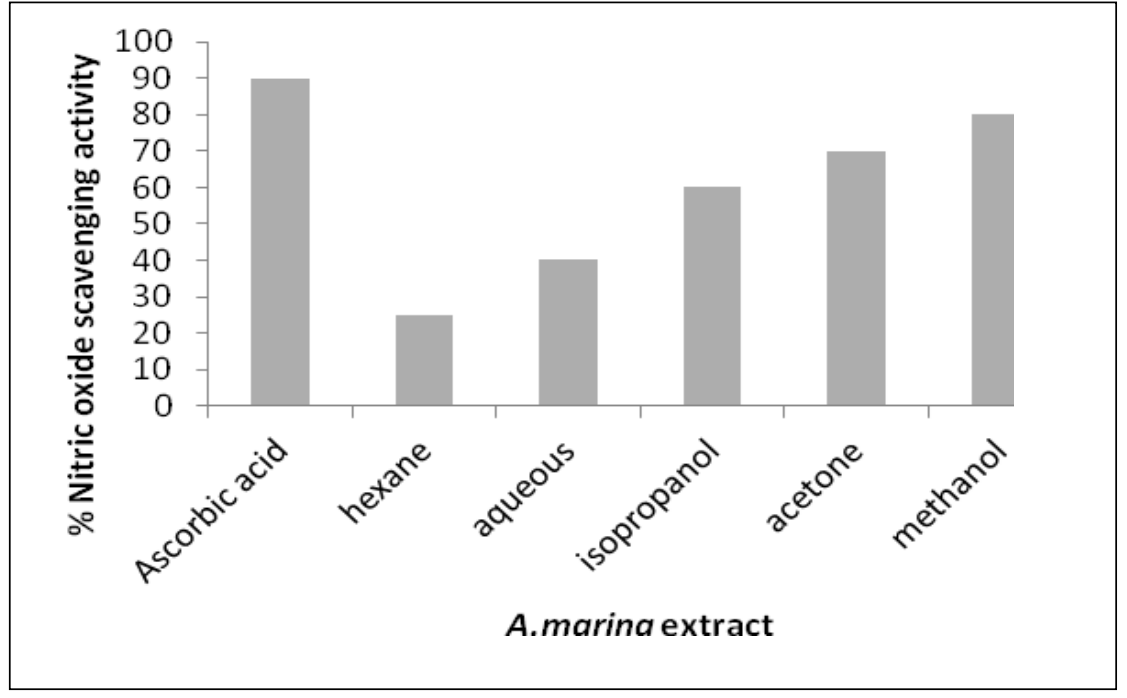

Figure 3. Protein denaturation inhibition activity

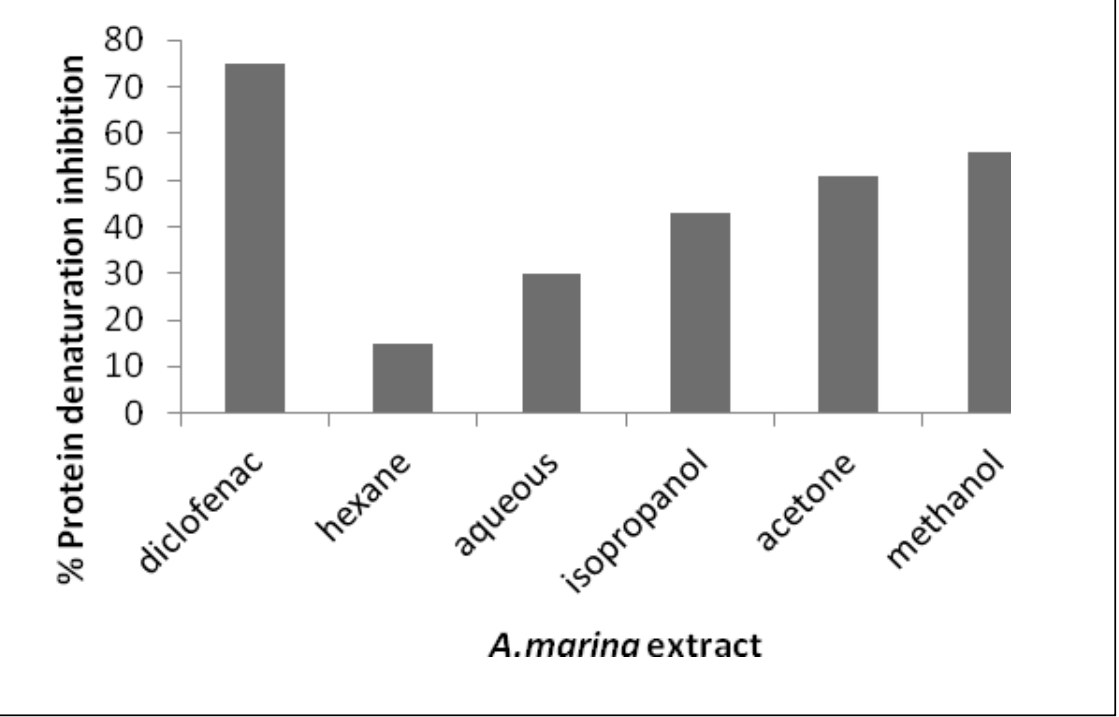


Figure 4. Metal chelation activity

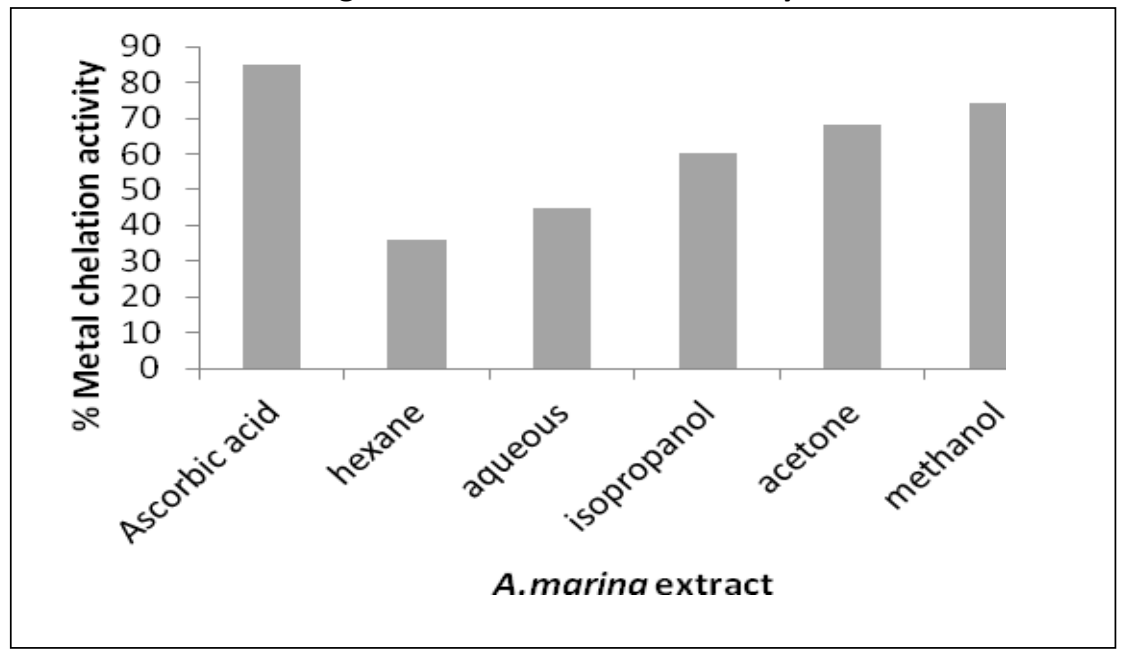

\section{ACKNOWLEDGEMENT:}

Our sincere thanks to Dr. D. S. Mahendran, Principal, Aditanar College of Arts and Science, Tiruchendur and Dr. S. Nagarajan, Principal, Kamaraj College, Thoothukudi, Tamil Nadu for providing infrastructure and facilities required for this research work.

\section{REFERENCES:}

1. Adam M, Gihan OM, Yagi ES, Senol FS, Abdel LEO, Ahmed A, Efferth T. In vitro Antioxidant and cytotoxic activities of 18 plants from the Erkowit Region, Eastern Sudan, Natural Products and Bioprospecting, 2018: 8,97-105.

2. Awah M, Verla AW. Antioxidant activity, nitric oxide scavenging activity and phenolic contents of Ocimum gratissimum leaf extract Francis. Journal of Medicinal Plants Research, 2010: 4(24), 2479-2487.

3. Bandaranayake WM. Bioactivities bioactive compounds and chemical constitutes in leaves of nine mangrove species. Marine and Freshwater Research, 2002:49 (5): 369 - 372.

4. Bharathi V, Patterrn J, Rajendran R. Optimization of extraction of phenolic compounds from Avicennia marina (Forssk) Vierh using responce surface methodology. International Journal of Biological and Medical Science, 2011:1: 1.

5. Borojeni AA, Behbahani $M$, Sadeghi-aliabadi $H$. Antiproliferative activity and apoptosis induction of crude extract and fractions of Avicennia marina. Iran Journal of Basic Medical Science, 2013: 16:12031208.

6. Chelliah S. Mangrove Forests: A Threatened Ecosystem. Yojana, 2001: 45: $30-31$.

7. Dinis TCP, Madeira VMC. Almeida LM. Action of phenolic derivatives (Acetaminophen, Salicylate and 5-Aminosalicylate) as inhibitors of membrane lipid peroxidation and as peroxyl radical scavengers. Archives of Biochemistry and Biophysics, 1994: 315, 161-169.

8. Duh PD, Tu YY, Yen GC. Antioxidant activity of water extract of Harng Jyur (Chrysanthemum morifolium
Ramat). Lebensmittel-Wissenschaft \& Technologie, 1999: 32:269- 277.

9. Duke NC. Mangrove floristics and biogeography In: A.I. Robertson and Alongi, D.M. (Eds) Tropical Mangrove Ecosystems. American Geophysical Union, Washington DC, 1998. 63-100.

10. Dyanathi N B, Ajith kumar TT, Ganesha murthy R, Kathirasan K. Isolation of antibacterial from the mangrove, Avicennia marina and their activity activity agaist multi drug resistant Staphylococcus aureus. Asian Pacific Journal of Tropical Biomedicine, 2012: 1892-S1895.

11. Edeoga HO, Okwu DE, Mbaebie BO. Phytochemical constituents of some Nigerian medicinal plants. African Journal of Biotechnology, 2005: 4: 685 - 688.

12. Garrat DC. The Quantitative analysis of Drugs. Chapman and Hall Ltd. Japan, 1964.1-669.

13. Harbone JB. Phytochemical methods, London. Chapman and Hall, Ltd, 1998:49 - 188

14. Ishibashi F, Satasook C, Isman MB, Neil Towers GH. Insecticidal Cyclopentatetrahydro [b] Benzofurans from odorota. Phytochemistry, 1993: 32: 307 - 310.

15. Kathiresan $\mathrm{K}$, Bingham BL. Biology of mangrove ecosystem. Advanced Marine Biology, 2001:40: 81 251.

16. Kokpal V, Miles DH, Payne AM, Chittawong V. Chemical constituents and bioactive compounds from mangrove plants. Study of Natural Products Chemistry, 1990: 7: 175 - 199.

17. Kumaran A, Karunakaran RJ. Antioxidant Activities of the Methanol Extract of Cardiospermumhalicacabum, Pharmaceutical Biology, 2006: 44:2, 146-151.

18. Kumaruzzaman BY, Rina Sharlinda MZ, Akbar John B. Accumulation and Distribution of Lead and Copper in Avicinnia marina and Rhizopora apiculata from Balok Mangrove Forest, Pahang, Malasia., Sains Malaysiana, 2011: 40(6):555 - 560.

19. Madduluri S, Silaran B, Balasekharan C. In vitro evaluation of anti-inflammatory activity of methanolic and ethanolic leaf extracts of five indigenous plants in South India. International Journal of Pharmaceutical Technical Research, 2014: 6920, 569-574. 
20. Marium T, Sahnaz Fatima SM, Javed zaki M. Use of Avicennia marina (Forsk) vierh in the control of Root Knot Nematode Meloidogyne javanica (Treup) Chitwood on Okra and Mash Bean, Turkish Journal of Biology, 2007: 31, 225 - 230.

21. Miki T, Sakaki T, Shibata M, Inukai $Y$, Hirosue H, Ikema $\mathrm{Y}$, Yaga S. Soxhlet extraction of mangrove and biological activities of extracts. Kyushu Kogyo Gijutsu Kenkyusho Hokoku, 1994: 53, 3347-3352.

22. Mitul P, Handral M. Anti-myotoxic and antiinflammatory activity of Cinnamomum zeylanicum extracts against Naja kaouthia snake venom. Indo American Journal of Pharmacological Research, 2013: 3(6), 4226 - 4237.

23. Mohan GL, Deepak M, Viswanatha GL, Savinay G, Hanumantharaju V, Rajendra CE, Praveen HD. Antioxidant and anti-inflammatory activity of leaf extracts and fractions of Mangifera indica. Asian Pacific Journal of Tropical Medicine, 2013: 6(4), 311314.

24. Pacher P, Beckman JS, Liaudet L. Nitric oxide and peroxynitrite: in health and disease. Physiology Review, 2007: 87: 315-424

25. Panda H. Medicinal plants cultivation and their uses, Asia Pacific Business Press Inc, 2000: 1-598

26. Prasad AK, Shankul Kumar S, Iyer SV, Sudani JR, Vaidya SK. Pharmacognostical, phytochemical and pharmacological review on Bryophyllum pinnata. International Journal of Pharmaceutical \& Biological Archives, 2012: 3(3):423 - 433.

27. Prieto $P$, Pineda $M$, Aguilar $M$, Spectrophotometric quantitation of antioxidant capacity through the formation of a phosphomolybdenum complex: specific application to the determination of vitamin $\mathrm{E}$, Annals of Biochemistry, 1999: 1;269(2):337-41
28. Samydurai $P$, Thangapandian V. Nutritional assessment, polypterosis evaluation and antioxidant activity of food resource plant Decalepis hamiltonii Wight \&Arn. Journal of Applied Pharmaceutical Science, 2012: 2: 106-110

29. Sarkar M. Evaluation of the anti-inflammatory activity of methanolic leaf extract of Mangifera indica $\mathrm{L}$. (Anacardiaaceae) in rats. International Journal of Drug Development Research, 2015: 7(3), 21-25.

30. Shanmugapriya R, Ramanathan T, Renugadevi G. Phytochemical characterization and antimicrobial efficiency of mangrove plants Avicennia marina and Avicennia officinalis. International Journal of Pharmaceutical Biology Archives, 2012: 3:348-351.

31. Sharma S, Vig AP. Evaluation of In vitro antioxidant properties of methanol and aqueous extracts of Parkinsonia aculeata L. leaves. The Scientific world Journal, 2013: 1, 1-7

32. Sreejayan N, Rao MNA.Nitric oxide scavenging by curcuminoids. Journal of Pharmaceutical Pharma cology, 1997: 49: 105-107.

33. Tanford C. Protein denaturation, Advanced Protein Chemistry, 1968, 23: 121-282.

34. Williams LAD, Connar AO, Latore L, Dennis O, Ringer S, Whittaker JA, Conrad J Vogler B, Rosner H, Kraus, $W$. The in vitro anti-denaturation effects induced by natural products and non-steroidal compounds in heat treated (immunogenic) Bovine Serum Albumin (BSA) is proposed as a screening assay for the detection of anti-inflammatory compounds, without the use of animals in the early stages of the drug discovery process. West Indian Medical Journal, 2008:57(4), 327-331. 